\title{
A Ponta do Iceberg: Manifestações Cutâneas de Patologia Pediátrica com Envolvimento Neurológico
}

\author{
The Tip of the Iceberg: Cutaneous Manifestations of Paediatric Diseases with \\ Neurological Involvement
}

Ana BRASILEIRO ${ }^{1}$, Paula AFONSO², Filipa DIAMANTINO ${ }^{1}$, Maria João PAIVA LOPES ${ }^{1}$

Acta Med Port 2015 Jan-Feb;28(1):92-98

RESUMO

Introdução: Algumas alterações cutâneas podem ser as primeiras manifestações clínicas de diversas entidades nosológicas com atingimento sistémico. O presente trabalho tem como objectivo rever a semiologia dermatológica relevante no contexto das doenças com envolvimento neurológico na infância.

Material e Métodos: Revisão dos artigos indexados à MedLine publicados nos últimos 12 anos e com relevância para o tema.

Resultados: Os principais grupos nosológicos relevantes para o tema compreendem as genodermatoses (com destaque para as síndromes neurocutâneas), as alterações da pigmentação, as doenças vasculares, as endócrinas, os défices enzimáticos congénitos e os disrafismos espinhais ocultos.

Discussão: O reconhecimento da semiologia cutânea específica é importante pois pode permitir um diagnóstico muito mais precoce. Palavras-chave: Criança; Doenças da Pele; Doenças do Sistema Nervoso; Síndromes Neurocutâneos.

\section{ABSTRACT}

Introduction: Some cutaneous lesions might be the first clinical manifestation of diseases with systemic involvement. This article aims to review the relevant dermatological semiology for the concerning diseases with neurological involvement in childhood.

Material and Methods: Review of the related literature indexed to MedLine published in the last twelve years.

Results: The main relevant nosologic groups include the genodermatosis (namely neurocutaneous syndromes), pigmentary, vascular and endocrine disorders, congenital enzymatic deficiencies and occult spinal dysraphisms.

Discussion: The recognition of specific cutaneous signs is important once may enable a much earlier diagnosis.

Keywords: Child; Nervous System Diseases; Neurocutaneous Syndromes; Skin Diseases.

\section{INTRODUÇÃO}

O interesse de conhecer as manifestações cutâneas específicas de algumas das doenças neurológicas prende-se com o facto de estas poderem ser a ponta do iceberg que levanta a suspeita de uma síndrome mais complexa subjacente.

A compreensão de alguns destas síndromes remete-nos para a Embriologia, já que a pele e o Sistema Nervoso Central (SNC) possuem origem embrionária comum na neuroectoderme, a partir da qual se desenvolvem outras estruturas que poderão também estar afectadas.

A evidência aponta para que anomalias da formação, migração ou diferenciação das células da crista neural estejam na base da patogénese destas síndromes. Depois do encerramento do tubo neural, as células da crista neural migram para formar diversas estruturas, das quais se destacam os melanócitos, neurónios e células da glia do sistema nervoso sensorial e autónomo, condrócitos e osteócitos do crânio, entre outras. ${ }^{1}$

Dependendo do tipo de alteração genética subjacente, do padrão de hereditariedade (ou de mutação somática), da fase do desenvolvimento em que esta ocorre e das estruturas cujo desenvolvimento determina ou influencia, estabelecem-se expressões clínicas diversas, com amplo espectro fenotípico a nível cutâneo, neurológico e de atingimento de outros órgãos.
O presente trabalho tem como objectivo rever a semiologia cutânea mais relevante no contexto das doenças com envolvimento neurológico manifestas em idade pediátrica, dada a expressão clínica da primeira e o impacto prognóstico das segundas, uma vez que a literatura é escassa nesta abordagem que consideramos ser útil na prática clínica.

\section{MATERIAL E MÉTODOS}

Foram pesquisados os artigos de revisão indexados à MedLine escritos em língua portuguesa ou inglesa, publicados nos últimos 12 anos, usando como palavras-chave 'Neurocutaneous diseases', 'Neurofibromatosis', 'Tuberous sclerosis', 'Ataxia telangiectasia syndrome', 'Stuge-Weber syndrome', 'PHACE syndrome', 'PELVIS syndrome', 'Incontinentia pigmenti', 'Ito hypomelanosis', 'Linear and whorled hypermelanosis', 'Epidermic nevus', 'Lysosomal storage diseases', 'Skin hypopigmentation', 'Multiple endocrine neoplasia', 'Fabry disease', 'Gaucher disease', 'Hartnup disease', 'Spinal dysraphism'. Foram excluídos os artigos com enfoque em manifestações raras, terapêutica e acompanhamento, uma vez que tal abordagem ultrapassa os propósitos da presente revisão. As referências bibliográficas dos artigos incluídos foram também analisadas e incluídas quando considerado pertinente.

1. Serviço de Dermatologia. Hospital S. António dos Capuchos. Centro Hospitalar de Lisboa Central. Lisboa. Portugal.

2. Serviço de Pediatria. Hospital do Barreiro. Centro Hospitalar do Barreiro-Montijo. Barreiro. Portugal.

Recebido: 08 de Janeiro de 2014 - Aceite: 15 de Junho de 2014 | Copyright $\odot$ Ordem dos Médicos 2015 


\section{RESULTADOS}

\section{Síndromes neurocutâneas}

a) Neurofibromatose tipo 1 (NF-1): Também designada doença de Von Recklinghausen, é uma síndrome neurocutânea com incidência de um caso em cada 2500 nascimentos. ${ }^{2}$ Afecta igualmente ambos os sexos, sem predileção pela raça. A transmissão é autossómica dominante (AD), embora se estime que cerca de $50 \%$ dos casos possam corresponder a mutações espontâneas. ${ }^{3} \mathrm{O}$ gene afectado é o NF-1, que codifica a neurofibromina, uma proteína com funções de supressão tumoral cuja mutação condiciona a formação de neurofibromas e displasia mesodérmica. ${ }^{4}$ Várias mutações estão descritas, com expressão variável e elevada variação inter e intrafamiliar. ${ }^{2}$

Em termos de envolvimento cutâneo, são várias as manifestações que devem levantar suspeita de NF-1, tais como as manchas café com leite, as efélides axilares ou os neurofibromas cutâneos, subcutâneos e plexiformes. ${ }^{5}$

As lesões mais frequentes são as manchas café com leite (Fig. 1a), que para constituírem critério de diagnóstico devem estar presentes em número igual ou superior a seis (uma vez que podem existir em menor número em até um quarto das crianças saudáveis) e apresentar $>5 \mathrm{~mm}$ de diâmetro nas crianças e $>15 \mathrm{~mm}$ após a puberdade. ${ }^{5,6,7}$ Estão presentes em $95 \%$ dos doentes e geralmente surgem até aos três anos de idade. ${ }^{8}$ Podem localizar-se em todo o tegumento cutâneo com exceção das palmas, plantas e couro cabeludo, mas são mais frequentes no tronco, região glútea e membros. ${ }^{9}$ São manchas com coloração castanha clara uniforme, bem delimitadas, de forma geralmente oval, cujo maior diâmetro pode medir desde 1 a $2 \mathrm{~mm}$ até mais de $20 \mathrm{~cm} .{ }^{10}$ Normalmente tornam-se notórias durante o primeiro ano de vida. ${ }^{7,11} \mathrm{O}$ diagnóstico de NF-1 é em geral feito mais tarde, tendo a idade média de diagnóstico sido aos 4,7 anos numa série portuguesa. ${ }^{12}$ Desta forma, bebés e crianças com seis ou mais manchas café com leite, mesmo sem história familiar ou outros critérios de diagnóstico, devem ser mantidas sob vigilância clínica, pois 95\% destas vão desenvolver NF-1. ${ }^{13}$

A segunda manifestação mais frequente é a presença de efélides ${ }^{5,6,12}$ (Fig. 1b), mais frequentemente axilares, mas que também podem ser encontradas na região inguinal, cervical ou palpebral. São geralmente evidentes entre os três e os cinco anos. ${ }^{7}$

Os neurofibromas são tumores benignos que se desenvolvem a partir das bainhas do nervo e compostas por uma mistura de células de Schwann, fibroblastos, mastócitos e pericitos. ${ }^{11}$ Podem ser cutâneos, subcutâneos ou plexiformes. ${ }^{13}$ Os mais comuns são os cutâneos, podendo ser sésseis ou pediculados. ${ }^{14}$ Os neurofibromas subcutâneos podem apresentar-se com desconforto ou parestesias ao longo do trajecto do nervo afectado, podendo ser detáveis através da palpação cutânea. ${ }^{15}$ Os plexiformes são geralmente patognomónicos de NF-1 e ocorrem em $40 \%$ dos doentes. Atingem todas as camadas da pele, com infiltração em profundidade, podendo causar erosão óssea ou obstrução gastrointestinal ou respiratória por efeito de massa. ${ }^{4} \mathrm{~A}$ pele que os recobre pode ser hipertrófica, hiperpigmentada e com aspecto de cútis laxa. ${ }^{16}$ São na sua maioria congénitos, embora muitas vezes só se tornem notórios aos 4-5 anos de vida. ${ }^{14} \mathrm{O}$ número de neurofibromas é variável entre indivíduos e dentro de famílias. ${ }^{13}$

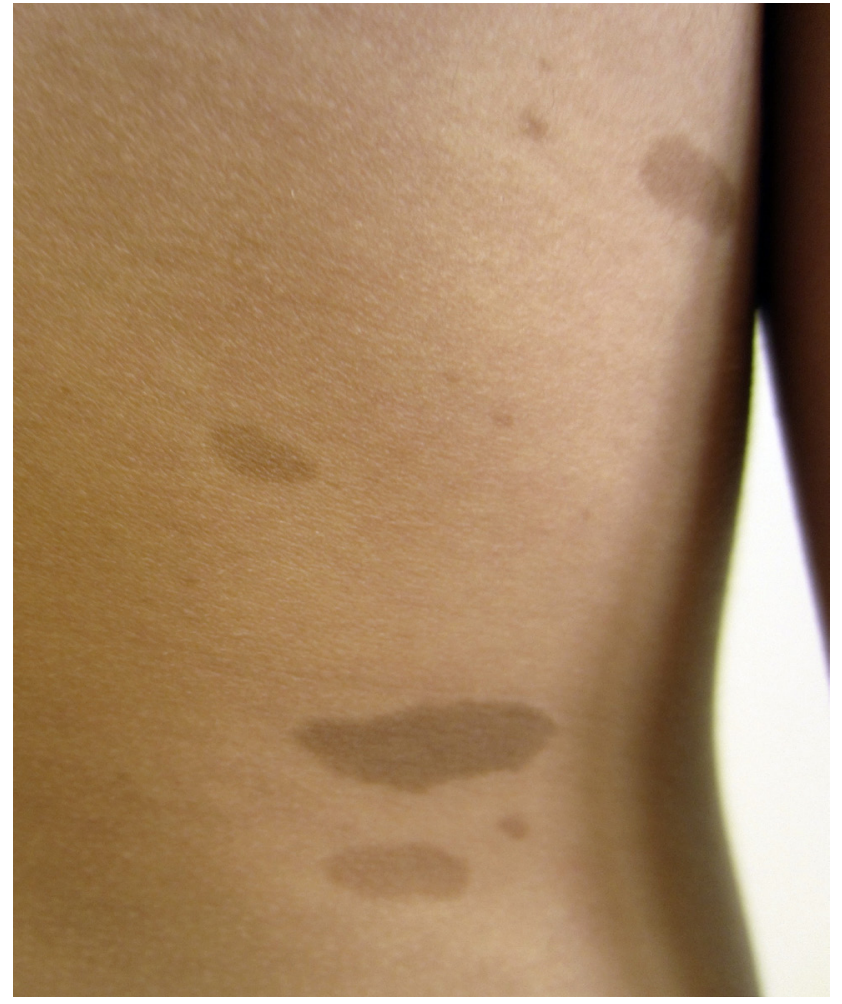

Figura 1a - Manchas café com leite na face posterior do tronco

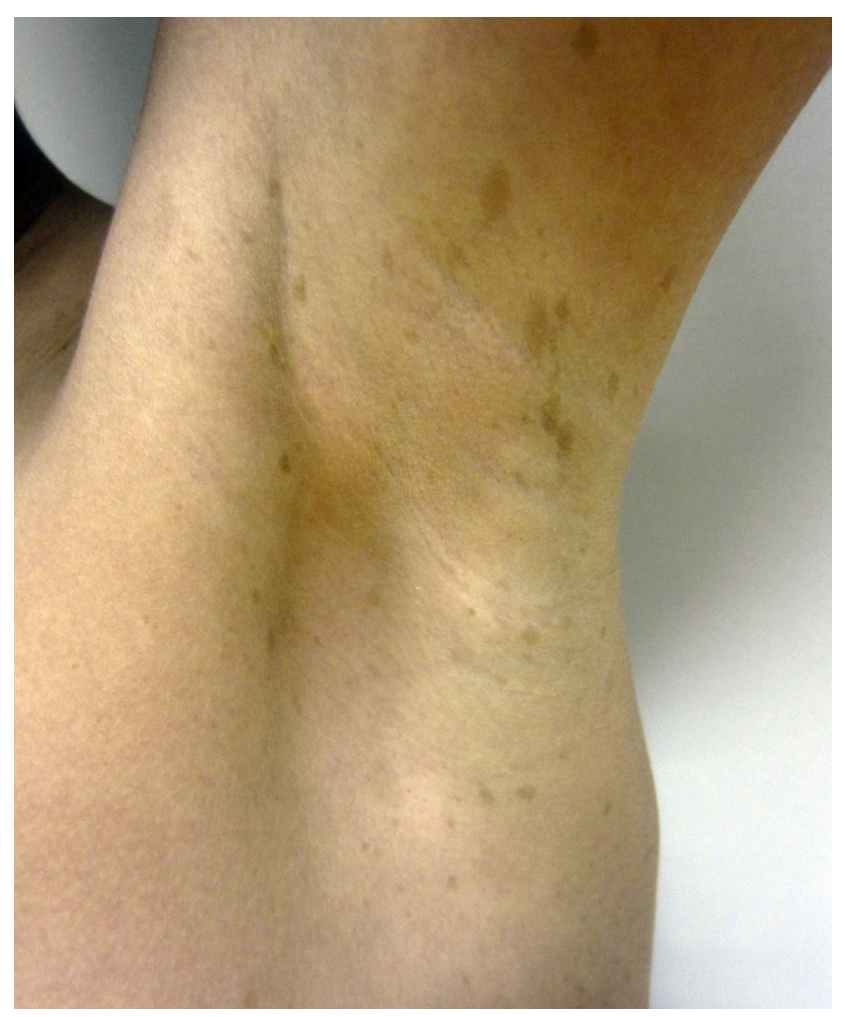

Figura 1b - Efélides axilares (sinal de Crowe) 
Tabela 1 - Critérios de diagnóstico de NF-1

- 6 ou mais manchas café com leite ( $>0,5 \mathrm{~cm}$ nas crianças e $>1,5 \mathrm{~cm}$ nos adultos)

- 2 ou mais neurofibromas cutâneos ou subcutâneos ou 1 neurofibroma plexiforme

- Efélides axilares ou inguinais

- Glioma óptico

- 2 ou mais nódulos de Lisch

- Lesões ósseas (displasia do esfenóide ou adelgaçamento do cortex de ossos longos)

- Familiar em primeiro grau afectado

(adaptado de Ferner 2007) ${ }^{9}$

Cada um dos três tipos de manifestações cutâneas supra citadas constitui critério diagnóstico de NF-1. É necessário a presença de pelo menos 2 critérios para que seja estabelecido o diagnóstico (Tabela 1).

Os restantes critérios são: nódulos de Lisch (>90\% dos casos), que são formações hamartomatosas melanocíticas a nível da íris, gliomas do nervo óptico, lesões ósseas e história de familiar em primeiro grau afectado. ${ }^{7}$

A nível neurológico destacam-se as dificuldades na aprendizagem $(30-60 \%)$, atraso do desenvolvimento ou défice cognitivo grave $(<5 \% \text { das crianças })^{14}$ e epilepsia $(6-7 \%) .{ }^{13}$ Os gliomas do nervo óptico surgem em cerca de $15 \%$ dos doentes. São geralmente assintomáticos, motivo pelo qual estes doentes requerem avaliação oftalmológica regular. ${ }^{13}$

A NF-1 atinge vários órgãos e sistemas, com alterações esqueléticas encontradas em até $50 \%$ dos doentes. ${ }^{4}$ Salienta-se a macrocefalia (38-45\%), ${ }^{17}$ a escoliose (10\%), e outras alterações menos frequentes mas que são muito sugestivas de NF, como a displasia da asa do esfenóide ou dos ossos longos. ${ }^{8}$

Podem ainda estar presentes diversas neoplasias endócrinas tais como o feocromocitoma, o hiperparatiroidismo, o carcinoma medular da tiróide e os tumores carcinóides produtores de somatostatina. ${ }^{18}$

b) Esclerose Tuberosa (ET): É também uma doença com transmissão $A D$, embora com percentagem elevada de mutações espontâneas (50-84\%). ${ }^{19}$ Pode estar mutado um de dois genes supressores tumorais (TSC1 e TSC2), ${ }^{20}$ que codificam respetivamente as proteínas hamartina e tuberina. ${ }^{21} \dot{E}$ menos frequente do que a NF-1, estimando-se que ocorra em um de cada 6000-100000 nascimentos. ${ }^{19}$

O envolvimento neurológico é muito frequente, manifestando-se como convulsões em 70 até quase $90 \%$ dos doentes $^{22}$ e défice cognitivo em $48 \%{ }^{6}$ Podem ocorrer hamartomas, mais frequentemente na pele, cérebro, rim e olho $^{20}$ ou outras alterações do desenvolvimento em quase todos os órgãos - rim (angiomiolipomas), SNC, coração (rabdomiomas), pulmões (linfangioleiomiomatose), ${ }^{23}$ gastrointestinal ${ }^{14}$ e ossos (quistos, nomeadamente a nível das falanges). ${ }^{19}$

As manifestações cutâneas estão presentes em $96 \%$ dos doentes. ${ }^{20}$ As máculas ou manchas hipopigmentadas são quase sempre a primeira manifestação. As mais frequentes são as manchas hipocrómicas do tronco, tipicamente descritas como em folha de freixo, podendo ser ovoides ou em losango. Constituem critério major de diagnóstico quando são em número igual ou superior a três. ${ }^{14}$

A hipopigmentação pode ocorrer também sob a forma de máculas arredondadas de limites bem definidos designadas em confetti, ${ }^{22}$ mais frequentemente localizadas nos membros inferiores. ${ }^{14}$ Esta manifestação é critério minor ${ }^{23}$ de diagnóstico.

Os angiofibromas ou adenomas sebáceos, também eles critério de diagnóstico major, ${ }^{23}$ são muito frequentes e localizam-se na zona centro-facial, tipicamente ao longo do sulco nasolabial ${ }^{23}$ (Fig. 2a); surgem geralmente depois dos três anos de idade e podem crescer rapidamente durante a puberdade. ${ }^{20}$ Podem apresentar-se sob a forma de placa de aspecto rugoso na região frontal, que resulta da sua confluência. ${ }^{14}$

Os fibromas peri-ungueais são também característicos, pelo que constituem critério major de diagnóstico, ${ }^{23}$ sendo designados por tumores de Koenen. Em geral surgem no final da infância e podem aumentar em número e dimensão até à idade adulta. São mais comuns nos pés. ${ }^{19}$ Estão também descritos, com incidência variável (10-70\%), fibromas a nível gengival.

Outra lesão característica é a peau de chagrin (Fig. 2b), designação que nos remete para a textura do couro de pele de cabra, a qual se localiza caracteristicamente na zona lombo-sagrada. É uma placa dérmica de tecido conjuntivo, de superfície rugosa. ${ }^{14,23}$ Surge por volta dos dois anos de idade e afecta cerca de $40-80 \%$ dos doentes com ET. ${ }^{14,23}$

Uma ressalva para as manchas café com leite, que foram descritas em até $30 \%$ dos doentes com ET; contudo, regra geral, são em número inferior a seis. ${ }^{14}$

\section{Doenças Vasculares}

a) Síndrome Ataxia-telangectasia: É uma síndrome rara (1:40000-1:100000), de transmissão autossómica 


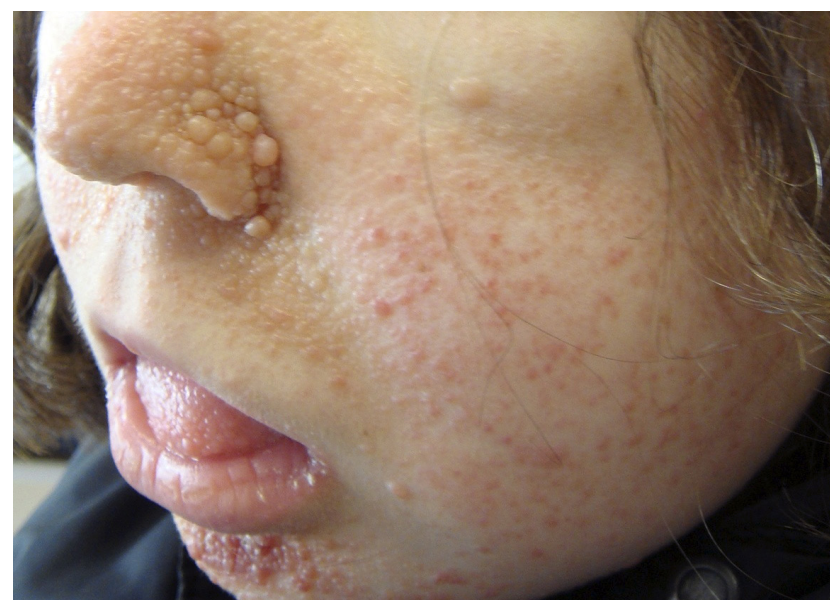

Figura 2a - Angiofibromas faciais com localização preferencial no sulco nasogeniano e mento

recessiva (AR). Ocorre por mutação do gene ATM, que codifica uma proteína reparadora de DNA. ${ }^{24}$ É uma doença multissistémica, caracterizada por disfunção neurológica progressiva, especialmente do cerebelo; telangiectasias oculares e cutâneas, imunodeficiência, infecções respiratórias recorrentes e alta incidência de neoplasias. ${ }^{25} \mathrm{~A}$ manifestação mais precoce é a ataxia, que se verifica quando a criança começa a andar. ${ }^{26}$

Contudo, o diagnóstico frequentemente não é estabelecido enquanto não surgem as telangiectasias (aos 3-6 anos), ${ }^{26}$ as quais inicialmente se manifestam na conjuntiva, posteriormente nos pavilhões auriculares, pálpebras, eminências malares, pregas antecubitais e popliteias e região pré-esternal. ${ }^{14}$

Outras manifestações cutâneas frequentes são os granulomas não infecciosos, que tendem a confluir em placas e a ulcerar. ${ }^{14}$

Existe em 50 a $80 \%$ dos $\operatorname{casos}^{26}$ um grau variável de imunodeficiência associado, verificando-se infecções respiratórias recorrentes ou crónicas em $38 \%$ dos indivíduos com mais de 20 anos. ${ }^{27}$

O envelhecimento cutâneo acelerado e a diminuição do tecido celular subcutâneo, bem como a despigmentação capilar, são alterações que ocorrem tipicamente na adolescência. ${ }^{14}$

b) Síndrome Sturge-Weber: Também designado por angiomatose encefalotrigeminal, é uma síndrome esporádica (embora tenham sido descritos raros casos de transmissão familiar, AD), com uma incidência de 1:50000 nascimentos. ${ }^{28}$ Caracteriza-se pela existência de uma mancha de cor vinho do Porto no território de um ou vários ramos do nervo trigémio (frequentemente o ramo oftálmico ou maxilar superior), alterações oftalmológicas (glaucoma congénito) e alterações neurológicas (convulsões, défice cognitivo e hemiparesia)..$^{29,30}$ A existência de uma mancha cor de vinho do Porto nesta localização é relativamente frequente (3:1.000 nascimentos), ${ }^{9,31}$ estimando-se que cerca de $8 \%$ dos casos de qualquer malformação vascular cutânea facial correspondam a esta síndrome. ${ }^{28}$

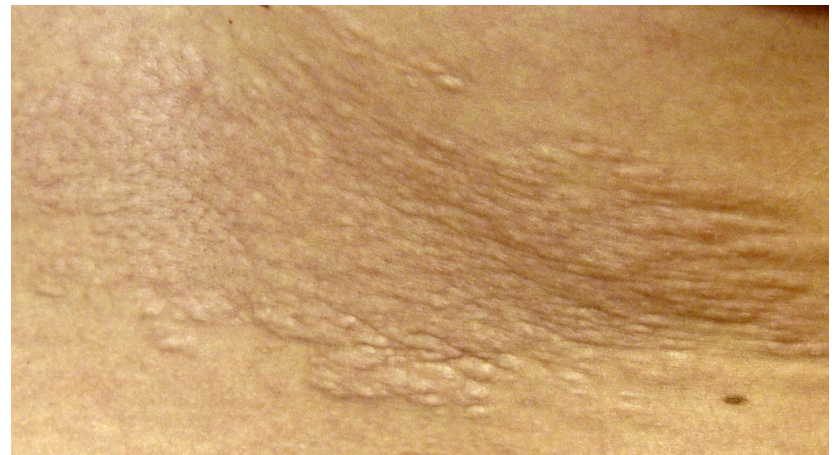

Figura 2b - Peau de chagrin.

A manifestação clínica mais frequente é a epilepsia refratária e de início precoce (em 70-90\% manifesta-se até aos três anos). ${ }^{28} \mathrm{~A}$ extensão do envolvimento cutâneo e ocular é variável. O envolvimento neurológico também é bastante variável, desde epilepsia intratável até desenvolvimento psicomotor normal sem epilepsia. ${ }^{9}$

c) Síndrome PHACE e Síndrome PELVIS: Ambas as designações são acrónimos que pretendem alertar para a existência de malformações associadas a hemangiomas com localizações específicas.

A síndrome PHACE caracteriza-se por malformações da fossa Posterior, Hemangioma, anomalias Arteriais, Cardíacas e do olho (Eye) O hemangioma é segmentar, localiza-se tipicamente na cabeça e pescoço, distribui-se ao longo de vários dermátomos, sendo por vezes bilateral. ${ }^{32}$ Desta forma, na presença de hemangioma extenso nesta localização devem ser pesquisadas as restantes malformações características.

A síndrome PELVIS manifesta-se por hemangioma Perianal, malformações dos genitais Externos, Lipomielomeningocelo, alterações Vesico-renais, ânus Imperfuratum e fibroma cutâneo (Skin). A presença de um hemangioma extenso do períneo deve levantar suspeita de disrafismo espinhal oculto e conduzir a actuação clínica em conformidade. ${ }^{33}$

\section{Alterações da pigmentação com mosaicismo}

A designação mosaicismo reflete a existência de células de dois ou mais genótipos diferentes no mesmo indivíduo, que tem subjacente uma mutação genética estrutural ou funcional. ${ }^{34} \mathrm{Na}$ pele, o mosaicismo pode assumir cinco principais fenótipos. ${ }^{34}$ No mais frequente, as alterações distribuem-se segundo as linhas de Blaschko, que provavelmente traduzem o padrão de migração dos queratinócitos aquando da embriogénese. ${ }^{34,35}$

a) Incontinência pigmentar: $A$ incontinência pigmentar, também designada de Síndrome de Bloch-Schulzberger, é classicamente uma síndrome de transmissão ligada ao $X$, pelo que se manifesta maioritariamente no sexo 
feminino. É rara, porém possível, a sua ocorrência no sexo masculino, com 42 casos descritos na literatura. ${ }^{36} \mathrm{~A}$ mutação ocorre no gene NEMO, que interfere em mecanismos inflamatórios e apoptóticos. ${ }^{37}$

Clinicamente apresenta quatro estádios de evolução, o primeiro dos quais se manifesta nas duas primeiras semanas de vida, caracterizando-se por vesículas e bolhas em base eritematosa com arranjo linear segundo as linhas de Blaschko. Localiza-se mais frequentemente nos membros e couro cabeludo, podendo também envolver o tronco. Em seguida surge o estádio verrucoso, (das 2 às 6 semanas), em que as lesões anteriores são substituídas por pápulas hiperqueratósicas (Fig. 3a). Posteriormente, dos 3 aos 6 meses, observam-se máculas e manchas hiperpigmentadas com o mesmo padrão de distribuição, embora não necessariamente nos mesmos locais. É nesta fase que a incontinência pigmentar é mais evidente, e que resulta da libertação de melanossomas pelos queratinócitos apoptóticos, depositando-se na derme. ${ }^{38}$ Por fim, na $2^{\mathrm{a}}-3^{\mathrm{a}}$ década de vida, as lesões hiperpigmentadas são substituídas por hipopigmentação, frequentemente com atrofia cutânea associada (Fig. 3b). ${ }^{39}$

Outras características fenotípicas que podem ajudar a estabelecer o diagnóstico são as alterações dentárias, como hipodontia, dentes cónicos e atraso na erupção dentária, que se podem encontrar em $80 \%$ dos doentes; a distrofia ungueal (7-40\%) e a alopécia do vértex (38\%) são menos frequentes. ${ }^{40,41}$ No que concerne às restantes manifestações extra-cutâneas, assumem especial importância as oftalmológicas - nomeadamente retinopatia isquémica e hemorrágica, descolamento da retina, atrofia óptica e estrabismo - já que estão presentes em aproximadamente $37 \%$ dos doentes. ${ }^{38} \mathrm{O}$ envolvimento neurológico, manifesto maioritariamente de forma precoce, ocorre em cerca de $30 \%$ dos doentes. As alterações mais frequentemente identificadas foram convulsões, atraso no desenvolvimento psico-motor e microcefalia. ${ }^{42}$

b) Hipomelanose de Ito, Hiperpigmentação linear nevóide e Síndrome do Nevo epidérmico: Estas síndromes são em geral causadas por mutações esporádicas (embora tenham sido reportados casos de Hipomelanose de Ito de transmissão AD, AR e ligada ao X). ${ }^{43}$ Têm em comum a

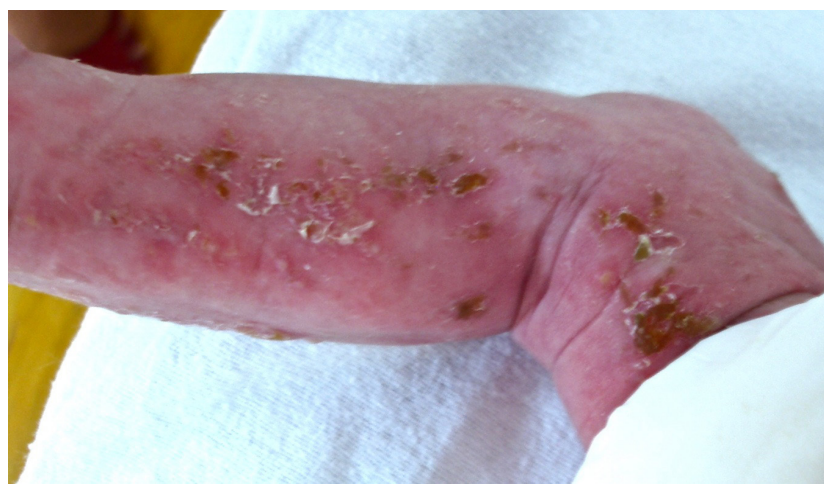

Figura 3a - Pápulas hiperqueratósicas em arranjo linear (estádio verrucoso) existência de mosaicismo pigmentar, caracterizando-se por hipo, hiperpigmentação ou placas verrucosas que seguem as linhas de Blaschko, respectivamente. ${ }^{34,44}$

As lesões cutâneas são congénitas ou surgem no primeiro ano de vida, em geral num hemitronco, estendendo-se por vezes aos membros homolaterais, podendo nalguns casos ser bilaterais. As manifestações extra cutâneas ocorrem em pelo menos um terço dos doentes, com incidência variável segundo as séries. Salienta-se o envolvimento neurológico (atraso no desenvolvimento e epilepsia), do sistema músculo-esquelético (assimetria facial e corporal) e as anomalias cardíacas. ${ }^{44-46}$

\section{Síndromes hereditários associados a hipopigmentação}

Diversas síndromes hereditárias com transmissão AR cursam com hipopigmentação cutânea generalizada. Várias etapas funcionais dos melanócitos podem estar alteradas, nomeadamente a biossíntese da melanina (Albinismo óculo-cutâneo e Fenilcetonúria), a formação dos melanossomas (S. Chédiak-Higashi, S. Hermansky-Pudlak), e a sua exocitose (S. Griscelli). ${ }^{1}$

Em geral estas síndromes cursam com outras manifestações, como sejam as oftalmológicas (nistagmo, fotofobia e diminuição da acuidade visual) no Albinismo óculo-cutâneo; ${ }^{47}$ e as hematológicas (neutropénia, infecções recorrentes e hipocoagulabilidade) nos S. Hermansky-Pudlak ${ }^{48}$ e Chédiak-Higashi, sendo o envolvimento neurológico variável. ${ }^{49} \mathrm{O} \mathrm{S}$. Griscelli pode também cursar com alterações neurológicas e hematológicas, dependendo do subtipo em causa. $^{1}$

Na Fenilcetonúria destaca-se o acometimento neurológico nos casos não tratados, sendo a microcefalia, o atraso no desenvolvimento e as convulsões manifestações clínicas frequentes. ${ }^{50}$

\section{Doenças endócrinas}

a) Síndrome de Neoplasias Endócrinas Múltiplas (NEM): A designação NEM define um conjunto de síndromes de transmissão $A D$, dos quais se salientam, pelo envolvimento cutâneo e neurológico, a NF1 (já abordada), e as NEM tipos 1 e $2 b$ :

1. NEM tipo 1: Embora o diagnóstico não seja em geral feito antes da $4^{\text {a }}$ década de vida, as manifestações

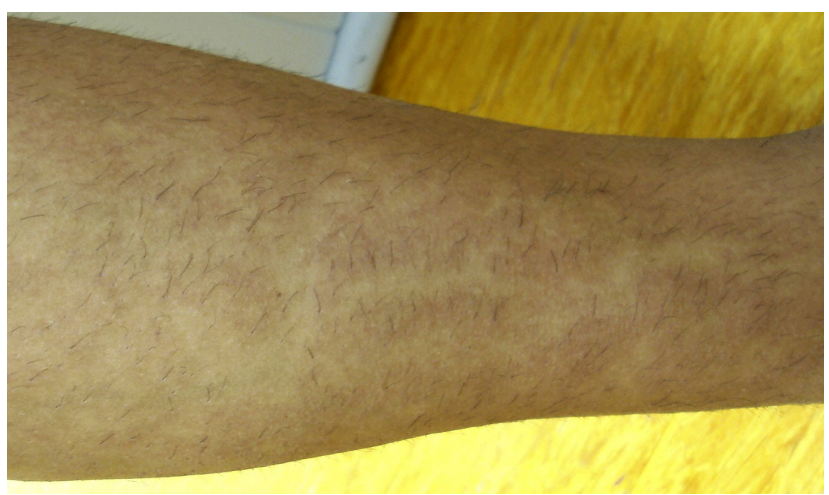

Figura 3b - Placa linear hipopigmentada. 
cutâneas destas síndromes podem evidenciar-se ainda antes da adolescência. ${ }^{51}$ Destacam-se os angiofibromas da face, que surgem em $64-88 \%$ dos doentes, ${ }^{45}$ sendo a lesão cutânea mais frequente. São múltiplos numa elevada percentagem dos casos. De referir também os colagenomas (nódulos normocrómicos ou hipopigmentados que se localizam no pescoço, tronco ou membros superiores), que atingem $63-72 \%$ dos doentes. ${ }^{51}$ Manifestações menos frequentes incluem lipomas, manchas café com leite, máculas hipopigmentadas e pólipos gengivais. ${ }^{52}$

A nível neurológico salientam-se os tumores da hipófise anterior, que juntamente com os do pâncreas e das glândulas paratiróides constituem as neoplasias características desta síndrome. ${ }^{51}$

2. NEM tipo 2b: É também frequentemente diagnosticado na idade adulta, contudo, os neuromas da mucosa labial e da língua podem surgir nos primeiros anos de vida. O envolvimento neurológico caracteriza-se principalmente pelo espessamento dos nervos da córnea, contudo outras manifestações mais graves com o carcinoma medular da tiróide em idade jovem justificam a importância do reconhecimento precoce dos sinais cutâneos. ${ }^{53}$

\section{Deficiências enzimáticas / de proteínas de transporte}

a) Doenças de depósito lisossómico: As doenças deste grupo definem-se pela ausência ou alteração da função de uma das enzimas lisossómicas, dando origem ao depósito tecidual de compostos não metabolizados. São em geral de transmissão AR. Destacam-se pelo envolvimento cutâneo: a doença de Fabry que se manifesta por angioqueratomas difusos - pápulas vermelho escuro com superfície queratósica, com localização preferencial no hipogastro, flancos, períneo e região glútea; ${ }^{54}$ e a doença de Gaucher, com amplo espectro de manifestações cutâneas, desde xerose e descamação congénita até bebé colodio. ${ }^{55}$

b) Doença de Hartnup: Causada por alteração no transporte de aminoácidos neutros a nível renal e intestinal, esta doença de transmissão AR apresenta ampla variabilidade de expressão clínica, de que se destaca a apresentação clássica de dermatose com eritema e descamação das áreas foto-expostas, descrita como pelagróide, associada a ataxia cerebelosa e alterações neurológicas inespecíficas. $^{56}$

\section{REFERÊNCIAS}

1. Dessinioti C, Stratigos A, Rigopoulos D, Katsambas A. A review of genetic disorders of hypopigmentation: lessons learned from the biology of melanocytes. Exp Dermatol. 2009;18:741-9.

2. Pasmant $E$, Vidaud M, Vidaud D, Wolkenstein P. Neurofibromatosis type 1: from genotype to phenotype. J Med Genet. 2012;49:483-9.

3. Jett K, Friedman JM. Clinical and genetic aspects of neurofibromatosis 1. Genet Med. 2010;12:1-11.

4. Patel NB, Stacy GS. Musculoskeletal manifestations of neurofibromatosis type 1. Am J Roentgenol. 2012;199:99-106.

5. Gerber PA, Antal AS, Neumann NJ, Homey B, Matuschek C, Peiper M, et al. Neurofibromatosis. Eur J Med Res. 2009;14:102-5.

6. Purkait R. Neurocutaneus syndrome: a prospective study. Indian J Dermatol. 2011;56:375-9.

7. Williams VC, Lucas J, Babcock MA, Gutmann DH, Korf B, Maria BL. Neurofibromatosis type 1 revisited. Pediatrics. 2009;123:124-33.

8. Ferner RE. Neurofibromatosis 1. Eur J Hum Genet. 2007;15:131-8.

\section{Disrafismo espinhal oculto}

Os disrafismos espinhais ocultos, também designados de espinha bífida oculta, resultam da fusão incompleta do tubo neural numa das fases da embriogénese. Os sinais cutâneos motivam frequentemente a investigação diagnóstica, já que estão presentes em $50-80 \%$ dos casos. ${ }^{57}$ Encontram-se mais frequentemente na região lombo-sagrada, podendo também encontrar-se a nível torácico e cervical. ${ }^{58}$ Aqueles que com maior probabilidade indicam a sua presença compreendem os lipomas, sinus dérmicos e os apêndices caudais. Os sinais que indicam risco médio-alto de disrafismos espinhal são: fosseta sacrococcígea atípica (profunda e com diâmetro $>0,5 \mathrm{~cm}$ ), hemangioma segmentar (associado ou não a síndrome PELVIS), desvio da prega glútea e aplasia cutânea. Outras manifestações associadas a menor risco são a hipertricose, mancha cor de vinho do Porto e lesões pigmentadas. A combinação de duas ou mais de qualquer das alterações supra descritas aumenta a probabilidade de disrafismo espinhal. ${ }^{57,58}$

Outros sinais que devem ser procurados na criança com suspeita de disrafismo espinhal são a escoliose, dor lombar, alterações da marcha, atrofia ou diminuição da sensibilidade nos membros inferiores e infecções urinárias de repetição. ${ }^{58}$

\section{DISCUSSÃO}

O reconhecimento da semiologia cutânea específica é fundamental dado que as manifestações cutâneas podem ser importantes pistas para o diagnóstico precoce de síndromes complexas, permitindo assim antecipar a intervenção dirigida com consequente possível impacto na evolução clínica da doença base.

\section{CONFLITOS DE INTERESSE}

Os autores declararam a inexistência de quaisquer conflitos de interesse.

\section{FONTES DE FINANCIAMENTO}

Os autores declararam a inexistência de quaisquer fontes de financiamento externos.

*Revisão parcialmente apresentada no Hospital D. Estefânia a 18 Dezembro 2012.

9. Nowak C. The phakomatoses: dermatologic clues to neurologic anomalies. Semin Pediatr Neurol. 2007;14:140-9.

10. Shah $\mathrm{KN}$. The diagnostic and clinical significance of café-au-lait macules. Pediatr Clin North Am. 2010;57:1131-53.

11. Lu-Emerson C, Plotkin SR. The Neurofibromatoses. Part 1: NF1. Rev Neurol Dis. 2009;6:E47-53.

12. Martins C, Monteiro JP, Farias A, Fernandes R, Fonseca MJ. Neurofibromatose tipo 1 em idade pediátrica. O que vigiar? Acta Med Port. 2007;20:393-400.

13. Ferner RE, Huson SM, Thomas N, Moss C, Willshaw H, Evans DG, et al. Guidelines for the diagnosis and management of individuals with neurofibromatosis 1. J Med Genet. 2007;44:81-8.

14. Bolognia JL, Jorizzo JL, Rapini RP. Dermatology. $3^{\text {rd }}$ ed. Amsterdam: Mosby Elsevier; 2012. p. 889-900.

15. Williams VC, Lucas J, Babcock MA, Gutmann DH, Korf B, Maria BL.Neurofibromatosis Type 1 Revisited. Pediatrics. 2009;123;124-33. 
16. Rosser T, Packer R. Neurofibromas in children with neurofibromatosis 1 . J Child Neurol. 2002;17:585.

17. Young $\mathrm{H}$, Hyman $\mathrm{S}$, North K. Neurofibromatosis 1: clinical review and exceptions to the rules. J Child Neurol. 2002;17:613.

18. Guimarães J. Neoplasias endócrinas múltiplas. Acta Med Port. 2007;20:65-72.

19. Hake S. Cutaneous manifestations of tuberous sclerosis. Ochsner J. 2010;10:200-4

20. Staley BA, Vail EA, Thiele EA. Tuberous sclerosis complex: diagnostic challenges, presenting symptoms, and commonly missed signs. Pediatrics. 2011;127:e117-25.

21. Curatolo $P$, Bombardieri R, Jozwiak $S$. Tuberous sclerosis. Lancet. 2008;372:657-68.

22. Ghosh SK, Bandyopadhyay D, Chatterjee G, Ghosh A, Sarkar S, Sarkar $\mathrm{S}$. Mucocutaneous changes in tuberous sclerosis complex: a clinical profile of 27 Indian patients. Indian J Dermatol. 2009;54:255-7.

23. Roach ES, Sparagana SP. Diagnosis of tuberous sclerosis complex. J Child Neurol. 2004;19:643.

24. Mavrou A, Tsangaris GT, Roma E, Kolialexi A. The ATM gene and ataxia telangiectasia. Anticancer Res. 2008;28:401-5.

25. Bott L, Thumerelle C, Cuvellier JC, Deschildre A, Vallée L, Sardet A. Ataxia-telangiectasia: a review. Arch Pediatr. 2006;13:293-8.

26. Huang KY, Shyur SD, Wang CY, Shen EY, Liang DC. Ataxia telangiectasia: report of two cases. J Microbiol Immunol Infect. 2001;34:71-5.

27. Nowak-Wegrzyn A, Crawford TO, Winkelstein JA, Carson KA, Lederman HM. Immunodeficiency and infections in ataxia-telangiectasia. J Pediatr. 2004;144:505-11.

28. Thomas-Sohl KA, Vaslow DF, Maria BL. Sturge-Weber syndrome: a review. Pediatr Neurol. 2004;30:303-10.

29. Dahan D, Fenichel GM, El-Said R. Neurocutaneous syndromes. Adolesc Med. 2002;13:495-509.

30. Maruani A. Syndrome de Sturge-Weber. Presse Med. 2010;39:482-6.

31. Comi AM. Update on Sturge-Weber syndrome: diagnosis, treatment, quantitative measures, and controversies. Lymphat Res Biol. 2007;5:257-64.

32. Poetke M, Frommeld T, Berlien HP. PHACE syndrome: new views on diagnostic criteria. Eur J Pediatr Surg. 2002;12:366-74.

33. Girard C, Bigorre M, Guillot B, Bessis D. PELVIS syndrome. Arch Dermatol. 2006;142:884-8

34. Kouzak S, Mendes M, Costa I. Cutaneous mosaicisms: concepts, patterns and classifications. An Bras Dermatol. 2013;88:507-17.

35. Vreeburg M, van Steensel MA. Genodermatoses caused by genetic mosaicism. Eur J Pediatr. 2012;171:1725-35.

36. Ardelean D, Pope E. Incontinentia pigmenti in boys: a series and review of the literature. Pediatr Dermatol. 2006;23:523-7.

37. Snyder S, Narayanan V, Jantarra G. Genetic aspects of neurocutaneous disorders. Semin Pediatr Neurol. 2006;13:43-7.

38. Meuwissen ME, Mancini GM. Neurological findings in incontinentia pigmenti; a review. Eur J Med Genet. 2012;55:323-31.
39. Happle R. X-chromosome inactivation: role in skin disease expression. Acta Pædiatr Suppl. 2006;95:16-23.

40. Berlin AL, Paller AS, Chan LS. Incontinentia pigmenti: a review and update on the molecular basis of pathophysiology. J Am Acad Dermatol. 2002;47:169-87

41. Ribeiro FC, Cunha FI, Flores MM, Bicho MA. Incontinência pigmentar ou síndrome de Block-sulzberger. Acta Pediatr Port. 2013;44:68-70.

42. Minić S, Trpinac D, Obradović M. Systematic review of central nervous system anomalies in incontinentia pigmenti. Orphanet J Rare Dis. 2013;8:25.

43. Parisi L, Di Filippo T, Roccella M. Hypomelanosis of Ito: neurological and psychiatric pictures in developmental age. Minerva Pediatr. 2012;64:6570.

44. Lernia V. Linear and whorled hypermelanosis. Pediatr Dermatol 2007;24:205-10.

45. Brandling-Bennett HA, Morel KD. Epidermal Nevi. Pediatr Clin N Am 2010;27:1177-98

46. Assogba K, Ferlazzo E, Striano P, Calarese T, Villeneuve N, Ivanov I, et al. Hypomelanosis of Ito: report of four new cases and review of the literature. Neurol Sci. 2010;31:9-16.

47. Grønskov K, Ek J, Brondum-Nielsen K. Oculocutaneous albinism. Orphanet J Rare Dis. 2007;2:43

48. Seward SL Jr, Gahl WA. Gahl Hermansky-Pudlak syndrome: Health care throughout life. Pediatrics. 2013;132:153-60.

49. Kaplan J, De Domenico I, Ward DM. Chediak-Higashi syndrome. Curr Opin Hematol. 2008;15:22-9.

50. Williams RA, Mamotte CD, Burnett JR. Phenylketonuria: an inborn error of phenylalanine metabolism. Clin Biochem Rev. 2008;29:31-41.

51. Asgharian B, Turner ML, Gibril F, Entsuah LK, Serrano J, Jensen RT. Cutaneous tumors in patients with multiple endocrine neoplasm type 1 (MEN1) and gastrinomas: prospective study of frequency and development of criteria with high sensitivity and specificity for MEN1. J Clin Endocrinol Metab. 2004;89:5328-36.

52. Winship IM, Dudding TE. Lessons from the skin - cutaneous features of familial cancer. Lancet Oncol. 2008;9:462-72.

53. Moline J, Eng C. Multiple endocrine neoplasia type 2: an overview. Genet Med. 2011;13:755-64

54. Boggio P, Luna PC, Abad ME, Larralde M. Fabry disease. An Bras Dermatol. 2009:84:367-76.

55. Staretz-Chacham O, Lang TC, LaMarca ME, Krasnewich D, Sidransky $\mathrm{E}$. Lysosomal storage disorders in the newborn. Pediatrics. 2009;123:1191-207

56. Patel AB, Prabhu AS. Hartnup disease. Indian J Dermatol. 2008:53:312.

57. Silva HM, Carvalho C, Carreira L. Disrafismo espinhal oculto - acuidade para o diagnostic. Acta Pediatr Port. 2012;43:263-7.

58. Bellet JS. Developmental anomalies of the skin. Semin Perinatol. 2013;37:20-5 


\section{A Ponta do Icelberg: Manifestações Cutâneas de Patologia Pediátrica com Envolvimento Neurológico}

Acta Med Port 2015:28:92-98

Publicado pela Acta Médica Portuguesa, a Revista Científica da Ordem dos Médicos

Av. Almirante Gago Coutinho, 151

1749-084 Lisboa, Portugal.

Tel: +351218428 215

E-mail: submissao@actamedicaportuguesa.com

www.actamedicaportuguesa.com

ISSN:0870-399X | e-ISSN: 1646-0758

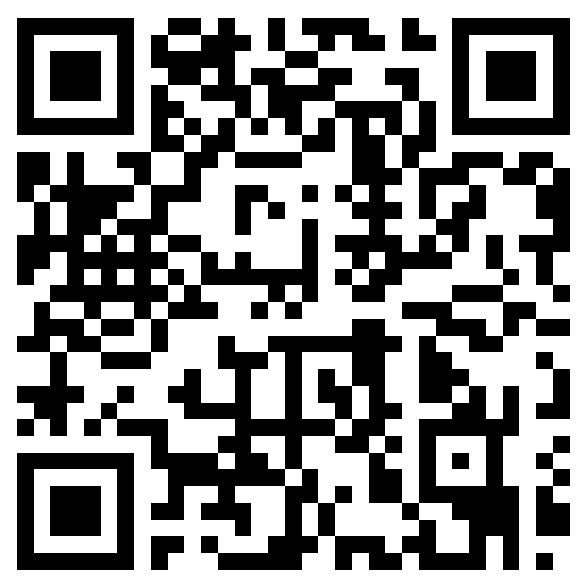

